The Journal of SPORT, 2013, 2(1), 60-77

(C) Kent State University

\title{
Lightning Safety: How is it conducted at NIAAA Member High Schools?
}

\author{
Mauro Palmero \\ East Tennessee State University
}

Andrew Dotterweich

East Tennessee State University

\author{
Gary Lhotsky \\ East Tennessee State University
}

\author{
Joseph Walker \\ University of North Texas
}

\begin{abstract}
The purposes of this study were to explore the current scenario of interscholastic athletics in regards to the existence and enforcement of lightning safety policies applied to athletic outdoor activities, and to identify the common practices related to lightning safety currently utilized. The results showed that $87.2 \%$ of the respondents $(N=804)$ have lightning safety policies. However, only $90.3 \%$ of the respondents who have lightning safety policies actually enforce them. It seems that during practices coaches are most commonly responsible for making the decision to stop/resume activity, and that during games athletic directors are most commonly making the call. However, almost one third of the respondents $(N=804)$ do not have a clear designation as to who makes the decision. A less than desirable percentage of respondents reported frequent use of a lightning detection system, availability of shelters for spectators, and posted lightning policy in facilities. Only 7.8\% of the respondents indicated that all athletic coaches and staff receive lightning safety training. The results also showed that more experienced administrators were more likely to have and enforce lightning safety policies, and employ lightning safety best practices. This study provides high school athletic administrators and principals with relevant information that can be used to support their decision to adopt and enforce lightning safety policies for interscholastic athletic activities
\end{abstract}




\section{Introduction}

Tens of thousands of thunderstorms and tens of millions of cloud-to-ground lightning flashes occur across the United States each year, but only a small fraction of the population is directly harmed or killed by lightning (Ashley \& Gilson, 2009; Holle, Lopez \& Zimmerman, 1999). After flooding, lightning is the second leading cause of weather-related death in the United States; approximately 400 injuries and 100 deaths are associated annually with lightning strikes in the United States (Holle et al., 1999; Walsh, Bennett, Cooper, Holle, Kithil \& Lopez, 2000). According to Ashley and Gilson (2009), harm and fatality due to lightning are caused by an increased number of unorganized storms, human vulnerability, and less warning and mitigation activities.

Despite its occurrence, "lightning is a leading source of storm deaths in the United States" (Roeder, Holle, Cooper \& Hodanish, 2012, p.1). The highest density of cloud-to-ground lightning strikes occurs in the southeastern and southern regions of the United States (Bennett, 1997; Roeder, Holle, Cooper \& Hodanish, 2012). The majority of the reported lightning accidents occur in the afternoon, which is the time of the day most of the student-athletes (involved in outdoor sports at high school and college levels) usually practice and compete (Bennett, 1997; Roeder \& Jensenius, 2012; Walsh et al., 2000). Thus, high schools have to be prepared to prevent lightning from harming, or worse taking the lives of teenage athletes (and their fans) who engage in outdoor interscholastic sports.

Outdoor sports are an integral part of the lives of high school students and have the potential to offer them many benefits. In addition to the well-known mental, physical, economic, and spectator benefits provided by outdoor high school sports, the possible costs or hazards related to lightning occurring during participation in outdoor interscholastic sports are always present (Lipsey, 2006; Ashley \& Gilson, 2009). With outdoor sports and recreation being the activities with the fastest rising lightning casualty rate today $(73 \%$ of the total deaths by lightning in the U.S., from 2006 to 2011) it is important for coaches, referees, and administrators of outdoor school activities to practice recommended 
lightning safety (Roeder \& Jensenius, 2012). Such support is essential in facilitating this process. Therefore, schools need an effective integrated lightning safety plan.

These facts cited above justify the need for increased efforts in developing and implementing lightning safety policies. Such policies should aim to prevent lighting from harming athletes, fans, and high schools engaged in outdoor sports. With that in mind, it is important for interscholastic athletic administrators to become familiar with commonly utilized lightning policies applied to high school sports. The following studies present the currently used approaches to lightning safety.

The Lightning Safety Group (LSG), composed of lightning experts in several lightning related fields, gathered in 1998 to develop one of the initial sets of guidelines for proper lightning safety (Zimmerman, Cooper \& Holle, 2002). The proposed best safety practices applied to both individuals and large groups include: (1) use of the 30-30 rule (If 30 seconds or less between lightning and thunder, seek shelter. Stay inside until 30 min after last lightning strike); (2) seek safer areas (larger grounded structures or fully enclosed metal vehicles); (3) avoid tall structures (e.g. trees, mountains, light poles, towers), open fields, open vehicles or open structures, contact with conducive materials (e.g. wires, metal, appliances), being near water; (4) develop a lightning safety plan; (5) train staff on established policies; (6) have access to reliable weather information; (7) if detection or warning systems are used, train staff in their use; (8) designate safer areas; (8) plan for evacuation; (9) display appropriate signage; (10) educate participants and spectators on the plan; (11) carry out regular lightning evacuation drills; and (12) review and modify the plan as needed (Zimmerman, Cooper \& Holle, 2002).

Roeder and Vavrek (2005) add to LSG"s guidelines by stating that "total lightning safety requires four tiers of activities: 1) education, so people are aware of the hazard and know what actions to take when lightning threatens, 2) weather warnings to alert people to take action, 3) protection of facilities and equipment, and 4) mitigation, for when that protection fails (p. 2)." 
On the same note, Roeder (2010) defends the implementation of 5 levels of lightning safety: (1) schedule outdoor activities in a way to avoid lightning, (2) "30-30 Rule" (If 30 seconds or less between lightning and thunder, seek shelter. While sheltered, stay away from corded telephones, electrical appliances and wiring, and plumbing. Stay inside until 30 min after last lightning strike), (3) avoid dangerous locations/activities (elevated places, trees, open areas, tall isolated objects, water activities), (4) Lightning Crouch (put your feet together, squat down, tuck your head, and cover your ears), (5) First Aid: Call 9-1-1 (use CPR or rescue breathing, as appropriate).

In 2012, Roeder et al. brought some important updates to the initially proposed 5 levels of lightning safety. The first update was to use "hearing thunder" as cue to seek a safe place (replacing waiting for 30 seconds between lightning and its thunder as in now superseded ,30-30 Rule,,). Another important update was to include an automatic external defibrillator (AED) to lightning first aid.

In their position statement on lightning safety for athletics and recreation, Walsh et al. (2000) recommend that proactive and comprehensive policies be formalized and implemented. The authors recommended the following policies: (1) define who makes the call when it is time to stop the activity, (2) monitor local weather forecasts, (3) designate an on-site "weather watcher" who will look for signs of threatening weather, (4) communicate lightning safety policies to fans verbally (PA system) and through signage (5) designate in-venue shelters, and (6) establish specific criteria for suspension (flash to bang count) and resumption of activities (30 minutes after the last thunder or flash of lightning).

In regards to the implementation of lightning safety policies, Roeder and Vevrek (2005) advise that: (1) management support is vital, so everyone involved acts in a coordinated effort; (2) involving coaches, referees, and leaders of other outside activities in the planning help in reducing resistance; (3) preparing handouts, posters, brochures, guidelines, etc., help expediting the implementation process; (4) resistance may occur, specially from those who mistakenly believe that lightning is not an important hazard or that 
nothing can be done to reduce the risks (you must remind them that failing to take reasonable and prudent precautions will make you guilty of negligence); and (5) education of students, teachers, coaches, referees, managers, leaders of other outside activities, and other staff on lightning safety is of ultimate importance.

With today"s technology advancements, inexpensive handheld lightning detectors have become very accessible and affordable to schools. However, their performance have been questioned by anecdotal evidence showing that such devices either seem to not always locate lightning accurately, or are used improperly. Some lightning safety organizations, such as the Lightning Safety Group, also question the performance of hand-held lightning detectors.

The Lightning Safety Group (LSG) does not recommend using these hand-held detectors as a substitute for the 30-30 Rule (Roeder \& Vevrek, 2005). LSG supports the use of commercially available professional grade lightning detectors, based on their good performance. However, these devices may be too expensive for most organizations. A less costly (but still high performance) alternative would be automatic lightning notification subscription services, which are more reliable than hand-held lightning detectors and much less expensive than professional grade detectors. Such service uses data from the National Lightning Detection Network (objectively and independently verified to provide good lightning detection and location), and automatically provides notification when cloud-toground lightning is detected within desired distances of the desired location during the desired time (Roeder \& Vevrek, 2005).

In an effort to provide a safe environment, high school athletic directors must constantly ensure that the facilities, equipment, and supplies, as well as the processes associated with sport activities are safe for the participants and fans (Stier et al, 2008). To achieve such a goal, extensive planning is essential (Stier et al, 2008). Due to the nature of outdoor athletic activities, coaches and schools must be constantly prepared to respond to threatening weather. Thus, it is important that they understand that following lightning safety policies is instrumental to minimizing risks and reducing loss. The choice of either not having or not enforcing such 
safety policies puts schools and their staff at risk of experiencing the anguish and pain involved in the time consuming process of defending a lawsuit (Doleschal, 2006, Walsh et al., 2000). The use of recommended lightning safety policies as part of a risk management plan do not absolutely guarantee that litigation will be avoided. However, good risk management practices can be effective aids in developing not only safer programs, but also act as an effective defense, should litigation occur (Doleschal, 2006; Walsh et al., 2000).

For high school athletic administrators, the challenge becomes providing sport programs that take lightning safety seriously. In other words, the task is to effectively ensure that: weather is monitored diligently; activities are stopped timely; athletes and fans are properly sheltered; and activities are resumed safely. "Organizations with recurring outdoor activities, including schools, need to have a lightning safety plan. This plan must be inplace, understood, and agreed to by all participants before it is needed. "Adults must be responsible for the lightning safety of the children entrusted to their care" (Roeder \& Vevrek, 2005, p. 2). The National Federation of State High Schools' Association, in its Sports Medicine Handbook, provides a one-page brief and simplified set of guidelines on "handling contests during lightning disturbances" (NFSH, 2010). In such document, the NFHS covers four main points: weather monitoring, criteria for interruption and resumption of play, and periodic reviews.

Despite the existence of guidelines provided by the highest interscholastic governing body, a few questions remain to be answered when it comes to lightning safety. Do high schools across the country actually have lightning safety policies and truly enforce them? What are the most common components of these policies?

The purpose of this study was to explore the current scenario of interscholastic athletics in terms of the existence and enforcement of lightning safety policies within high school athletic departments. Another purpose was to identify the common components making up the lightning safety policies currently utilized. This study provides high school athletic administrators and principals with relevant 
information that can be used to support their decision to adopt and enforce lightning safety policies applied to outdoor interscholastic athletic activities.

To achieve such purposes, the following questions must be answered:

1- How frequently high schools have and enforce lightning safety policies which are tailored to their athletic programs?

2- What are the best policies/practices used by high school athletic departments to address the inherent risks related to lightning to the outdoor athletic activities they provide?

3- Is there any relationship between athletic directors" years of experience and existence/enforcement of lightning safety policies?

4- Is there any relationship between athletic directors" education and existence/enforcement of lightning safety policies?

\section{Methods}

The purpose of this study was to examine lightning policy and practices among high school athletics. To accomplish this, an online survey was developed and distributed to high school athletic administrators who were members of the National Interscholastic Athletic Administrators Association (NIAAA). The reason for choosing the NIAAA was its membership size and its ability to reach to administrators located in all states.

\section{Subjects}

The subjects were high school athletic directors belonging to the National Interscholastic Athletic Administrators Association (NIAAA). The NIAAA granted permission to the researchers to conduct the study. At the time of the survey, the NIAAA membership totaled 5,758 (while there were few email delivery failures, the amount was negligible). The first page of the online survey presented the participants information about the study and an informed consent form. Continuing to take the survey served as the respondents" consent. The survey was available to the participants 
for six consecutive weeks, and the participants received two email reminders.

\section{Instrument}

The survey used in this study was developed by modifying, with permission, an existing survey created by Spengler, Connaughton, Zhang and Gibson (2002), when studying lightning safety policies and procedures in Florida"s municipal recreation and park agencies.

Eleven questions of the survey focused on lightning policy and practices and eight were demographic questions. The questions were a combination of Likert-type and open-ended. Directions for each section of the survey were included within the survey at the start of the section. Directions were also placed at any change in format. The questionnaire"s content was developed using both previous literature and expert input from practitioners. Content validity was established using a panel of individuals chosen for their expertise and experience in lightning policy and procedures. Student focus groups were used to test for issues of readability.

\section{Data Collection and Analysis}

The survey was sent to the NIAAA membership using a modified Dillman (2007) method and was delivered by email. Each email consisted of a link to the survey and was accompanied by a letter explaining the purpose, an informed consent statement, anonymity statement, and contact information of the research team. Participants were issued electronically generated respondent ID numbers by the survey program. There were 5,758 surveys sent out with 962 surveys returned for a $16.7 \%$ response rate. Of the 962 surveys returned there were 804 fully completed and useable surveys. Demographic information was analyzed using descriptive analyses. A series of ANOVAs, t-tests and Chi-square tests were performed to investigate the existence of relationships between the lightning practices and administrators experience, education and sex. 


\section{Results}

The schools in the survey were varied in student population. The student populations ranged from 41 students to more than 8,000 with a mean enrollment of 1,182 . The schools were represented by athletic administrators who were mostly male (83.9\%), well educated (77.2\% held a graduate degree), and averaged over eleven years of total experience, with an average of eight years of employment at their current school.

\section{Lighting Safety Practices}

A variety of survey questions were asked relating to standard lightning safety practices. The questions were grouped into three categories: policy and procedure, equipment and facilities, and safety expectations and supervision. Policy and procedure questions included: the existence and enforcement of a lightning policy, both game and practice suspension/continuation decision-making power, and method of safe to return to play decision. The equipment and facility section included questions on detection system use, athlete and spectator shelter, and posted policies. Lastly, the safety expectation and supervision category included questions on safety training, supervised activities, and the perceived probability of and injury resulting from lightning strikes.

While most schools had (87.2\%) and enforced (90.3\%) lightning policy, there were discrepancies with decision-making. The vast majority of schools $(73.4 \%)$ did utilize the thirty minutes after last strike guideline. However, the ADs seemed to be the choice to make a game time decision to stop or resume for lightning by a narrow margin $(53.7 \%)$ while coaches were in charge of practices $(53.3 \%)$. In addition, roughly a third of the schools used some combination of $\mathrm{AD}$, coach, athletic trainer or other administrator to make game (32.0\%) and practice $(28.7 \%)$ decisions (Table 1).

The questions in the equipment and facilities category raised some potential issues related to lightning safety. Only about a third $(38.7 \%)$ of schools frequently or always used a lightning detection system (the survey did not ask for any specific type of device).Of 
those, only $31.1 \%$ regularly inspected their equipment. While most schools (73.4\%) had safe shelter for student-athletes, less than half $(43.1 \%)$ had safe areas for spectators to take shelter. A very concerning result is the lack of posted lightning policy in facilities. Only $2.7 \%$ always posted policies. Thirty-two percent said they did post policies sometimes (18.9\%) or often (13.8\%), but almost twothirds indicated that they never $(41.1 \%)$ or seldom $(23.2 \%)$ posted their policies (Table 1).

In the final category of safety expectations and supervision, $95 \%$ of schools indicated that activities were supervised. With that said, only $7.8 \%$ of schools indicated that all athletic coaches and staff had received lightning safety training. Survey respondents were asked about the perceived potential of a lightning strike and resulting injury from a strike. Seventy percent believed that there was a moderate to high potential for a strike. Just over half (56.8\%) also believed that there was a moderate to high probability of injury from a strike (Table 1).

Table 1

Percent of Administrators Engaging in Lightning Practices Regularly

\begin{tabular}{llr}
\hline Category & Practice & Percentage \\
\hline Policy and & & \\
& & $87.2 \%$ \\
& Existence of Lightning Policy & $90.3 \%$ \\
Enforcement of Lightning Policy & \\
Game stop/continuation decision & $53.7 \%$ \\
$\quad$ Athletic Director & $0.5 \%$ \\
Coach & $6.4 \%$ \\
Trainer & $7.4 \%$ \\
Other Administrator & $32.0 \%$ \\
Combination & \\
Practice stop/continuation decision & $4.6 \%$ \\
Athletic Director & $53.3 \%$ \\
Coach & $12.3 \%$ \\
Trainer & $1.2 \%$ \\
Other Administrator & $28.7 \%$ \\
Combination &
\end{tabular}


Table 1 (Continued)

Equipment and

Facilities

$\begin{array}{lr}\text { Flash to Bang } & 1.8 \% \\ 10 \text { minutes after strike } & 1.5 \% \\ 30 \text { minutes after strike } & 73.4 \% \\ \text { Coach or Admin. Decision } & 7.7 \% \\ \text { Other } & 6.6 \% \\ \text { Combination of methods } & 8.9 \%\end{array}$

Detection Systems frequently or always used

$38.7 \%$

Frequent inspection of detection equipment

$31.1 \%$

Have safe areas to shelter athletes in most venues

$72.7 \%$

Have safe areas to shelter spectators in most venues

$43.1 \%$

Lightning safety policies/procedures

posted at all facilities

Safety Expectations and Supervision

Lightning safety training provided to all coaches and staff

Activities are supervised by staff

$95.0 \%$

Perceived probability of a lightning

strike

None or Low

$30.0 \%$

Moderate to High

$70.0 \%$

Perceived probability of injury from a lightning strike

None or Low

$43.2 \%$

Moderate to High

$56.8 \%$ 
Lightning Safety Practices and Administrators' Experience

To examine relationships between lightning policy/practices and administrators" experience, t-test and chi-square analyses were performed. Administrators were categorized into two groups: those with fewer than eleven years of experience and those with eleven or more years. Results indicated significant associations between experience and existence of a plan, plan enforcement, detection, and inspection.

There was a significant $(\chi 2(1)=15.59, \mathrm{p}<.001)$ and weak $(\mathrm{Phi}=-.126, \mathrm{p}<.001)$ association between the level of administrator experience and the existence of a lightning policy. Of those with no plan, $71.8 \%$ were likely to be in the $0-10$ year category. Based on the odds ratio, the odds of administrators with 11 or more years of experience having a lightning policy in place was 2.44 times that of administrators with ten years or less experience. Experience also showed a significant $(\chi 2(1)=12.36, \mathrm{p}<.001)$ and weak $(\mathrm{Phi}=-.124$, $\mathrm{p}<.001$ ) association with the enforcement of the policy. Over $72 \%$ of those with no policy enforcement were administrators with $0-10$ years of experience. The odds of administrators with 11 or more years of experience enforcing a lightning policy were 2.49 times that of administrators with less experience.

T-tests indicated that there were differences between administrator experiences and use of detection technology $(\mathrm{t}=-2.58$, $\mathrm{p}<.05)$, inspection of monitoring systems $(\mathrm{t}=-2.63, \mathrm{p}<.01)$, and staff training programs $(\mathrm{t}=-3.59, \mathrm{p}<.05)$. The more experienced administrators were more likely to employ detection technology (mean difference $=-.39$ ), inspect the monitoring systems (mean difference $=-.33$ ) and conduct staff training (mean difference $=$ .36).

No differences were found between experience and safe shelters for players, safe shelters for spectators, staff training, posted policies, supervision, believed probability of a strike, believed probability of injury from strike, the person who calls practices, calls games, or resume to practice/play policies. 


\section{Lightning Safety Practices and Administrators' Education}

An ANOVA analysis indicated that there were no significant differences between education levels with regards to lightning detection technology use, inspections, player or spectator shelters, staff training, posted policies, supervised activities, probability of strike, or probability of injury due to strike.

\section{Discussion}

The first goal of this study was to determine the frequency with which high schools in America have and enforce lightning safety policies applied to their athletic programs. Regarding the existence of lightning safety policies, the results showed that $12.8 \%$ of the respondents did not have these policies. In addition, among the schools possessing lightning safety policies, $9.7 \%$ said the policies were not enforced.

Despite appearing to be low, these figures are unexpected and very concerning. The concern is based on the fact that lightning is the second leading cause of weather-related death in the United States (Holle et al., 1999; Walsh et al., 2000). In addition to that, interscholastic athletic stakeholders" expect that schools and programs to be fully committed to the safety of athletes and fans, and the results presented here do not fully meet such expectations. Thus, it would be only reasonable to expect that schools would fully commit to the enforcement of lightning safety policies. Today, it is very common to see media reports on interscholastic athletic budget cuts and the reduction of sport programs. That could be used as justification for the lack of more modern (and costly) weather monitoring equipment, but not to justify not having/enforcing lightning safety policies. Some simple (and free) lightning monitoring techniques, such as the thirty minutes after last strike guideline, are efficient preventive measures to mitigate the lightning hazard (Bennett, 1997; Roeder \& Vavrek, 2005).

The second goal of this study was to identify the best and most frequently used practices to address the inherent risks related to lightning during outdoor interscholastic athletic activities. As expected, the survey results showed that most administrators have 
and enforce lightning safety policies. However, the results presented a few points of concern.

The first point of concern is in regards to who is responsible for making the decision to stop/resume activities due to lightning. The results showed us that during practices coaches are most commonly responsible for making the decision and that during games athletic directors are the ones most commonly making the call. However, it is a very concerning fact that almost one third of the respondents do not have a clear designation as to who (athletic director, coach or athletic trainer) makes the decision to stop/resume during games and practices. It appears that whoever is the highest athletic department official present (athletic director or coach) makes the call. Such situations can be extremely confusing to everyone involved, and it may seriously jeopardize a school"s ability to defend itself in the case of litigation caused by lightning-related injury.

Another point of concern is the fact that only $38.7 \%$ of schools frequently or always used a lightning detection system. That can be justified based on the cost associated with having and maintaining the equipment. In addition, the lack of financial resources of many interscholastic athletic programs may put other priorities ahead of having a lightning detection system.

In addition, the results indicate a lack of safe shelter for athletes and spectators, with more than a quarter of the respondents (26.6\%) lacking available shelters for athletes and 56.9\% for spectators. Again, lack of funds and other budget priorities may be assigned as the culprit.

Another very concerning result is the lack of posted lightning policy in facilities. The overwhelming majority of respondents $(97.3 \%)$ did not regularly post their lightning policies at their outdoor venues. Any reasonable person would expect athletes and spectators to have access to policies which would give them information about lightning hazard and guide them to safety in the event of inclement weather (Bennett, 1997; Roeder \& Vavrek, 2005).

Perhaps the most alarming result is related to lightning safety training. Among all respondents, 92.2\% indicated that they do not 
provide athletic coaches and staff with lightning safety training. Such lack of training may render schools defenseless if facing negligence claims related to injuries/death caused by lightning (Bennett, 1997; Roeder \& Vavrek, 2005). Perhaps such lack of concern with training can be justified by the respondents" perception of the potential of a lightning striking and injuring someone during outdoor activities. The results of this study showed that it seems that the respondents view lightning strikes as highly possible to occur, but with moderate probability of causing injury $(70 \%$ believed that there was a moderate to high potential for a strike, and $56.8 \%$ believed that there was a moderate to high probability of injury from a strike).

The third goal of this study was to identify if there is any relationship between athletic directors" experience and existence/enforcement of lightning safety policies. A significant relationship was found between experience and the existence and enforcement of lightning safety policies. Administrators with less than 11 years of experience seem to be less likely to either have or enforce (or both) lightning safety policies than more experienced administrators. Such a result was unexpected, considering that the existence of lightning safety policies is too important in preventing injury, death and loss at any institution to depend on the athletic director"s experience (Cotton \& Wolohan, 2007; Doleschal, 2006). In addition, more experienced administrators were also more likely to employ detection technology, inspect the monitoring systems, and conduct staff training. The existence of such associations is not surprising. It is reasonable to expect that the experiences acquired through years on the job would lead administrators to the adoption of these best practices.

The fourth goal of this study was to identify if there is any relationship between athletic directors" experience and their level of education. There were no significant differences between education levels with regards to lightning detection technology use, inspections, player or spectator shelters, staff training, posted policies, supervised activities, probability of strike, or probability of injury due to strike. There were also no relationships between 
education levels and either personnel who call off or resume playing policy/practices. Such results support the idea that perhaps experience would lead administrators to the adoption and enforcement of lightning safety best practices.

\section{Recommendations for Future Research}

The results of this study revealed that a very high percentage of high school athletic departments surveyed do not provide athletic coaches and staff with lightning safety training. It would be interesting to conduct a qualitative study among various state high school associations to learn their perspective on the situation, their perceived reasons for such lack of training. To complement the study, athletic directors could be surveyed on their perceptions of the reasons suggested by the state high school associations" leadership. After comparing the results from both groups, a list of potential actions to help increase lightning safety training development, implementation and enforcement could be composed.

\section{Conclusion}

The present study demonstrated that, overall, interscholastic outdoor activities are conducted with the support of lightning safety policies, but we cannot say that all athletes and spectators involved in high school sports are completely safe from lightning related injuries. A large majority of respondents seem to be employing lightning safety best practices consistently, but there is a less than desired level of adoption of some practices (i.e., use of lightning detection system, availability of shelters for spectators, and posted lightning policy in facilities). It is very concerning to learn that almost a third of the respondents reported unclear guidelines on who decides when it is time to stop or resume activity due to lightning. Even more concerning is the coaches and staff lack of training on lightning safety reported by the respondents. It appears that the athletic directors" years of experience plays a role in the existence and enforcement of lightning safety policies and best practices. It is the researchers" hope that the evidence presented here opens the athletic directors" minds to the importance of the adoption of 
lightning safety policies as the only reliable way to minimize loss to athletes, spectators, and institutions.

\section{References}

Anderson, B. (2006). Policies and philosophies related to risk management in the athletic setting. Athletic Therapy Today, 11(1), 10-16.

Ashley, W. S. \& Gilson, C. W. (2009). A reassessment of U. S.

lightning mortality. American Meteorological Society, October.

Bennett, B.L. (1997). A model lightning safety policy for athletics. Journal of Athletic Training,32(3), 251-253.

Cotton, D. J. \& Wolohan, J. T. (2007). Law for Recreation and Sport Managers (5 $5^{\text {th }}$ ed.). Dubuque, IA: Kendall/Hunt Publishing Company.

Dillman, D. A. (2007). Mail and internet surveys: The tailored design method (2nd ed.). Hoboken, NJ: John Wiley and Sons.

Doleschal, K. L. (2006). Managing risk in interscholastic athletic programs: 14 legal duties of care. Marquette Sports Law Review, 17 (1), 295-339.

Holle, R. L., Lopez, R. E. \& Zimmermann, C. (1999). Updated recommendations for lightning safety. Bulletin of the American Meteorological Society, 80(10), 2035-2041.

Lipsey, J. H. (2006). Confronting the risk of high school athletics. Southern Medical Journal, 99 (2), 111.

National Federation of State High Schools' Association (2012).

NFSH guidelines on handling contests during lightning disturbances. Retrieved on May 10, 2012, from

http://www.nfhs.org/search.aspx?searchtext=NFHS Sports Medicine Handbook

Roeder, W. P. (2010). Lightning safety procedures for the public.

21th International Lightning Detection Conference, 19-20 Apr 10.

Roeder, W. P., Holle, R. L., Cooper, M. A. \& Hodanish, S. (2012).

Lessons learned in communicating lightning safety effectively. 
22th International Lightning Detection Conference, 2-3 Apr 12.

Roeder, W. P. \& Jensenius, J. (2012). A new high-quality lightning fatality database for lightning safety education. 22th International Lightning Detection Conference, 2-3 Apr 12. Roeder, W. P. \& Vavrek, R. J. (2005). Lightning safety for schools: An update. 14th Symposium on Education in Meteorology, 913 Jan 05.

Spengler, I.O., Connaughton, D.P., Zhang, J., \& Gibson, H. (2002). An analysis of lightening safety policies and procedures in Florida municipal park and recreation agencies. Journal of Park and Recreation Administration, 20(3), 38-50.

Stier, W. F., Schneider, R. C., Kampf, S., Haines, S. \& Gaskins, B. (2008). Selected risk management policies, practices, and procedures for intramural activities at NIRSA institutions. Recreational Sports Journal, 32, 28-44.

Walsh, K. M., Bennett, B., Cooper, M. A., Holle, R. L., Kithil, R, \& Lopez, R. (2000). National athletic trainers association position statement: Lightning safety for athletics and recreation.

Journal of Athletic Training, 35(4), 471-477.

Zimmerman, C., Copper, M. A. \& Holle, R. (2002). Lightning safety guidelines. Annals of Emergency medicine, 39(6), 660-664. 